\title{
Analyses of measuring tools comparing the quality of life in patients with multiple sclerosis
}

\author{
V. Hancinova', L. Simor ${ }^{2}$
}

1 Department of Neurology, Faculty of Medicine, Slovak Medical

Original Articles University and University Hospital in Bratislava, Bratislava, Slovak Republic

2 Department of Revision Medicine and Dentistry, Faculty of Medicine, Slovak Medical University, Bratislava, Slovak Republic

Submitted: 1.2.2016 Revised: 14.3.2016 Accepted: 5.5.2016

\section{Reviewers:}

G. Herdics

Slovak Tropic Institute, St Elizabeth Univ - Emergency Refugees Health Post Röszke,

Vámosszabadi, Hegyeshalom, Hungary

Y. Trilisinskaya

St. D. Comboni Project, Dental OPD Wau, South Sudan

\section{Key words:}

multiple sclerosis, quality of life, MSQLI, MSQOL, FAMS

\section{Abstract}

Multiple sclerosis (MS) is an autoimmune disease affecting the central nervous system (CNS). It is characterized by degeneration of axons and axal demyelination. Prevalence of multiple sclerosis is 30 per 100000 people in the world. In this article we aim to analyze and compare the selected measuring tools evaluating the quality of life in patients affected by MS. The studied measuring tools are: the Multiple Sclerosis Quality of Life Inventory (MSQLI), the Health-Related Quality of Life Questionnaire for Multiple Sclerosis (HRQOL-MS), the Multiple Sclerosis Quality of Life (MSQOL), the Functional Assessment of Multiple Sclerosis (FAMS), the Multiple Sclerosis Impact Scale (MSIS), the Multiple Sclerosis Functional Composite (MSFC), the Multiple Sclerosis International Quality of Life (MUSIQOL). Based on the selected studies we aim to compare the quality of life in MS patients. This article is directed towards the patients affected by MS and the specialist public. It aims to facilatate the navigation between the measuring tools evaluating the quality of life with multiple sclerosis.

\section{Introduction}

Multiple sclerosis (MS) is an autoimmune disease affecting the Central Nervous System (CNS). It is characterized by degeneration of axons and axal demyelination (22). The charecteristic features of MS are multiple inflammatory infiltrates located in the CNS particularly within white matter. These inflammatory infiltrates contain activated T-lymphocytes, macrophages and to a lesser extent B-lymphocytes. Additionally, the defects of the hematoencephalitic 
barrier are found in the acute focuses in CNS. As the MS is a multi-factorial disease, hence the exact determination of causing factor/s is difficult. With stroke occupying first place, Multiple sclerosis is positioned in second place (together with Parkinson's Disease) on the list of most debilitating diseases. Even though the main characteristic of MS is the lesion located in the white matter, in recent years with the development of new ways of screening techniques and specialized histopathological studies, research has been focusing more on the degeneration and lesions of grey matter. In particular, some research has shown that the grey matter lesions may lead to extended progression of physical disability; cognitive deficit; exhaustion; even epileptic seizures $(4,9)$. The MS treatment and symptom management is predominantly based on treatments of attacks through immuno-modulation (prophylactic) treatment to influence the natural progression of the disease and its rehabilitation (11). The latest clinical trials which showed positive effects of marijuana in MS treatment are not yet clear (21). In recent years, the treatment of MS has markedly progressed accentuating the necessity of early diagnosis, early subsequent treatment using new MS medication allowing for the natural progression of disease (12).

The prevalence of multiple sclerosis is 30 per 100000 people in the world (Slovak Republic 128 per 100 000), predominantly young individuals between 20 - 40 years of age, with women being twice as often afflicted as men (14). In recent years, the incidence of MS has grown mainly in the countries of the northern and middle geographical areas. The least affected people with MS are in the area of the Equator with the prevalence of 2 -15 per 100000 people (19).

Quality of life is an important consideration for patients with a chronic disease such as multiple sclerosis. In the latter period, the focus of many medical disciplines evolve around the term quality of health care (23) and quality of life. Quality of life within the medical field contains aspects of physical and psychological health of an MS patient mainly related to the term "health related quality of life". However, quality of life has a multi-dimensional character and is affected by many factors e.g. nutrition (20); physical; emotional; sexual; racial; economic; work; family; cultural; social. In general, in understanding of the quality of life, no less important is subjective valuation of quality of life by MS patients themselves. This subjective valuation stems from the unique and personal cognitive make up of each patient with the importance being given to patient's adaptability to life events and the support of their close ones.

In this article, we analyzed and compared the selected measuring tools evaluating the quality of life in patients affected by MS. The studied measuring tools are: the Multiple Sclerosis Quality of Life Inventory (MSQLI); the Health-Related Quality of Life Questionnaire for Multiple Sclerosis (HRQOL-MS); the Multiple Sclerosis Quality of Life (MSQOL); the Functional Assessment of Multiple Sclerosis (FAMS); the Multiple Sclerosis Impact Scale (MSIS); the Multiple Sclerosis Functional Composite (MSFC); the Multiple Sclerosis International Quality of Life (MUSIQOL).

\section{The measuring tools evaluating quality of life in patients with MS}

Tests used to evaluate clinical symptoms of MS fall into two categories: those that measure impairments of body function and body structures; those that measure activity limitations and restrictions. Among the tests in the first category are e.g. the Expanded Disability Status Scale and the Multiple Sclerosis Functional Composite. Examples of tests in the second category are 
the MSQOL, the Multiple Sclerosis Quality of Life Inventory.

The Multiple Sclerosis Quality of Life Inventory MSQLI is a battery consisting of 10 individual scales providing a quality of life measure that is both generic and MS-specific. The MSQLI was developed by the Consortium of Multiple Sclerosis Centers (CMSC) Health Services Research Subcommittee. It was designed to supplement but not replace traditional MS outcome measures. The MSQLI includes the medical outcome study short form-36 (SF-36) and 9 symptom-specific scales. The first 7 scales of the symptom-specific scales that complete the MSQLI address fatigue; pain; sexual satisfaction; bladder control; bowel control; visual impairment; perceived cognitive deficits. For these 7 scales higher scores indicate more severe problems in each of these areas. For the last 2 scales, which assess mental health status and perceived social support, higher scores are indicative of better mental health status and a stronger social support system respectively. If the standard longer forms are used the MSQLI takes approximately 45 minutes to administer. Using all 5 of the short forms the time can be reduced to approximately 30 minutes (6). The MSQLI is a commonly used HRQOL Instrument in MS studies.

The Health-Related Quality of Life Questionnaire for Multiple Sclerosis is a multi-dimensional construct that includes aspects of life quality or function affected by health status such as physical health and symptoms; psychosocial factors; and psychiatric conditions (7). This construct provides a broader measure of disease burden than physical impairment or disability level approximating the World Health Organization's definition of health as including physical; mental; and social well-being and not just the absence of disease or infirmity. Chronic illnesses such as MS have multi-dimensional impacts affecting physical and social functions as well as emotional well-being. Measures of HRQOL record patient's perceptions of their overall health and how their health affects their daily lives. A study of QOL measures in MS research found that the use of QOL Questionnaires provided a more comprehensive measure of the impact of MS than relying solely on assessments of physical impairment or disease activity and its effects. People with MS tend to rate aspects of their HRQOL lower than do people in the general population and even those with other chronic conditions $(10,3)$.

Multiple Sclerosis Quality of Life is a multi-dimensional health-related quality of life measure that combines both generic and MS-specific items into a single instrument. This 54-item instrument generates 12 subscales along with two summary scores, and two additional single-item measures (Table 1). The subscales are: physical function; role limitations-physical; role limitations-emotional; pain; emotional well-being; energy; health perceptions; social function; cognitive function; health distress; overall quality of life; sexual function. The summary scores are the Physical Health Composite Summary and the Mental Health Composite Summary. The MSQOL-54 is a structured, self-report questionnaire that the patient can generally complete with little or no assistance. It may also be administered by an interviewer. However, patients with visual or upper extremity impairments may need to have the MSQOL-54 administered as an interview. Interviewers should be trained in basic interviewing skills and in the use of this instrument. There is no single overall score for the MSQOL-54. Two summary scores - Physical Health and Mental Health - can be derived from a weighted combination of scale scores. In addition, there are 12 subscales: physical function; role limitations-physical; role limitations-emotional; 
pain; emotional well-being; energy; health perceptions; social function; cognitive function; health distress; overall quality of life; sexual function. There are also two single-item measures: satisfaction with sexual function and change in health (16).

The Functional Assessment of Multiple Sclerosis is one of the disease-specific quality of life instruments available. It has been described as the best instrument for assessing quality of life of patients with MS as it covers many of the quality of life domains relevant to patients with MS and has shown good convergent validity. The FAMS Instrument was developed in Chicago to be included in clinical trials and clinical processes. FAMS relates to six domains: mobility; symptoms; emotional wellbeing (depression); general contentment; thinking/ fatigue; family/ social wellbeing. The final version comprises 59 statements where the respondents are asked to indicate how true each statement has been for them during the past 7 days using the following 5 categories: not at all; a little bit; and somewhat; quite a bit; very much. The scoring algorithm for the FAMS assigns a value between 0 and 4 to each response category. The scores of negatively worded statements are reversed so, a high score consistently reflects good functional status/quality of life. The scores are added within each of the six subscales and then aggregated into a total FAMS score. One subscale (thinking/ fatigue) has a range of $0-36$, while the others have a range of $0-28$. The total FAMS score ranges between 0 and 176. In the case of missing response items a subscale score is derived based on the valid responses and adjusted so that the score maintains its full range $(15,24)$.

The Multiple Sclerosis Impact Scale is a disease-specific health-related quality of life instrument developed using the patient's perspective on disease impact. It consists of two subscales assessing the physical (MSIS-29-PHYS) and psychological (MSIS-29-PSYCH) impact of MS. A1though previous studies have found support for the psychometric properties of the MSIS-29 using traditional methods of scale evaluation. The Multiple Sclerosis Impact Scale is a new measure of the physical and psychological impact of MS from the patient's perspective. It was developed using the standard psychometric approach of reducing an item pool generated de novo from people with multiple sclerosis (MS). Psychometric evaluation of the scale was conducted in two large independent postal surveys of randomly selected, geographically stratified members of the Multiple Sclerosis Society. In those samples, the MSIS-29 satisfied all recommended psychometric criteria for rigorous measurement. However, the psychometric properties of health measurement instruments are sample dependent and cannot be established in a single study (18).

Another important instrument is the Multiple Sclerosis Functional Composite which was developed by the MS Society's Clinical Assessment Task Force as an additional clinical measure of MS disability progression. The MSFC comprises quantitative functional measures of three key clinical dimensions of MS: leg function/ambulation; arm/hand function; cognitive function. Scores on component measures are converted to standard scores (z-scores), which are averaged to form a single MSFC score. Preliminary analyses confirm that the three clinical dimensions of the MSFC are relatively independent the MSFC is sensitive to clinical changes over 1- and 2-year intervals and the MSFC has acceptable criterion validity (i.e., predicts both concurrent and subsequent EDSS change). The advantages and potential limitations of incorporating quantitative functional outcome measures such as the MSFC into collaborative databases are discussed. 
The Multiple Sclerosis International Quality of Life provides a global index score which is calculated as the mean of the individual dimension scores. The MUSIQOL Questionnaire comprises 31 questions in 9 dimensions (subscales): activities of daily living; psychological well-being; symptoms; relationships with friends; relationships with family; sentimental and sexual life; coping; rejection; relationships with the healthcare system (Table 2). The index score is computed as the mean of these subscale scores. All 9 dimensions and the index score are linearly transformed and standardized on a 0 to 100 scale where 0 indicates the worst possible level of quality of life (QOL) and 100 indicates the best level. Differential item functioning analysis were performed in the initial validation study showing satisfactory results across countries (2).

Table 1. Validated health-related quality-of-life Instruments (1)

\begin{tabular}{|c|c|c|c|c|c|c|c|c|c|}
\hline & \multicolumn{8}{|c|}{ Multiple sclerosis - specific instrument } & \\
\hline & $\begin{array}{l}\dot{1} \\
\stackrel{\delta}{\delta} \\
\cong\end{array}$ & & & $\begin{array}{l}\dot{1} \\
\delta \\
\sum^{\mathscr{2}}\end{array}$ & & 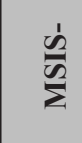 & $\frac{\frac{1}{n}}{2}$ & & \\
\hline & $\sum_{\Sigma}^{\infty}$ & $\sum^{\infty}$ & $\begin{array}{l}0 \\
\varnothing \\
\sum_{3}^{0}\end{array}$ & in & $\begin{array}{l}\vec{O} \\
\sum \\
\sum\end{array}$ & ৯े & $\overrightarrow{0}$ & $\tilde{2}$ & $\stackrel{2}{\searrow}$ \\
\hline Sexual function & & & & $\mathbf{X}$ & $\mathbf{X}$ & & $\mathbf{X}$ & $\mathbf{X}$ & \\
\hline Cognition & $\mathbf{X}$ & & & $\mathbf{X}$ & $\mathbf{X}$ & & & $\mathbf{X}$ & \\
\hline Communication & & & & & & & & & \\
\hline Emotional well - being & $\mathbf{X}$ & & $\mathbf{X}$ & $\mathbf{X}$ & $\mathbf{X}$ & & $\mathbf{X}$ & & \\
\hline Fertility & & & & & & & & & \\
\hline Global QOL or VAS & & & & $\mathbf{X}$ & & & $\mathbf{X}$ & & \\
\hline Health perception or distreee & & & $\mathbf{X}$ & $\mathbf{X}$ & & & & & $\mathbf{X}$ \\
\hline Mental health & & $\mathbf{X}$ & $\mathbf{X}$ & $\mathbf{X}$ & $\mathbf{X}$ & & & $\mathbf{X}$ & \\
\hline Mobility & $\mathbf{X}$ & $\mathbf{X}$ & & $\mathbf{X}$ & $\mathbf{X}$ & & & & \\
\hline Overal functioning & & & & & $\mathbf{X}$ & & $\mathbf{X}$ & & \\
\hline Pain & & & & $\mathbf{X}$ & $\mathbf{X}$ & & & & \\
\hline Physical function & & $\mathbf{X}$ & & $\mathbf{X}$ & $\mathbf{X}$ & $\mathbf{X}$ & $\mathbf{X}$ & & $\mathbf{X}$ \\
\hline Psychological function & $\mathbf{X}$ & $\mathbf{X}$ & $\mathbf{X}$ & & & $\mathbf{X}$ & $\mathbf{X}$ & & $\mathbf{X}$ \\
\hline QALY & & & & & & & & & \\
\hline Self-care & & $\mathbf{X}$ & & $\mathbf{X}$ & & & & & \\
\hline \begin{tabular}{|l|} 
Sensations \\
\end{tabular} & & & & & & & & & \\
\hline Sleep & & & & & & & & & \\
\hline \begin{tabular}{|l|} 
Social function \\
\end{tabular} & $\mathbf{X}$ & & $\mathbf{X}$ & $\mathbf{X}$ & $\mathbf{X}$ & & $\mathbf{X}$ & & $\mathbf{X}$ \\
\hline Spasticity & & & & & & & & $\mathbf{X}$ & \\
\hline Symptoms & $\mathbf{X}$ & & & & & & $\mathbf{X}$ & $\mathbf{X}$ & \\
\hline Visual function & & & & & $\mathbf{X}$ & & & $\mathbf{X}$ & \\
\hline \begin{tabular}{|l|} 
Vital or energy \\
\end{tabular} & & $\mathbf{X}$ & $\mathbf{X}$ & $\mathbf{X}$ & $\mathbf{X}$ & & & $\mathbf{X}$ & \\
\hline Instrumen length $^{\mathrm{a}}$ & & & & & & & & & \\
\hline short & & & $\mathbf{X}$ & & & & $\mathbf{X}$ & $\mathbf{X}$ & \\
\hline moderate & $\mathbf{X}$ & $\mathbf{X}$ & & & & $\mathbf{X}$ & & & \\
\hline long & & & & $\mathbf{X}$ & $\mathbf{X}$ & & & & $\mathbf{X}$ \\
\hline
\end{tabular}


Abbreviations: FAMS - Functional Assessment of Multiple Sclerosis, HRQOL-MS Health Related Quality of Life in Multiple Sclerosis, LMSQOL - Leeds Multiple Sclerosis Quality of Life, MSIS-29 - Multiple Sclerosis Impact Scale, MSQLI - Multiple Sclerosis Quality of Life Inventory, MSQOL-54 - Multiple Sclerosis Quality of Life-54, MUSIQOL - Multiple Sclerosis International Quality of Life, PS - Performance Scales, QOL - quality of life, RAYS - RAYS scale

a Short, $<10$ minutes; moderate, 10-44 minutes; long, $\geq 45$ minutes.

Table 2. Description of MS-specific instruments used in the assessment of health-related quality of life (1)

\begin{tabular}{|c|c|c|c|}
\hline Instrument & MSQOL-57 & MSQLI & MUSIQOL \\
\hline Description & $\begin{array}{l}5 \text { unchanged dimensions } \\
\text { from the SF-36, } 3 \text { altered } \\
\text { SF-36 dimensions, } \\
\text { and } 4 \text { new MS-specific } \\
\text { dimensions }\end{array}$ & $\begin{array}{l}\text { SF-36 and disease specific } \\
\text { measures }\end{array}$ & 9 disease specific measures \\
\hline Number of items & 54 & 138 & 31 \\
\hline $\begin{array}{l}\text { Approximate time } \\
\text { to complete (min) }\end{array}$ & $11-18$ & 45 & $10-11$ \\
\hline \multirow[t]{7}{*}{ Dimensions } & \begin{tabular}{|l|} 
SF-36 \\
Emotional well-being \\
Health perceptions \\
Physical function \\
Role limitations - \\
emotional \\
Role limitations - physical
\end{tabular} & SF-36 & - \\
\hline & $\begin{array}{l}\text { Modified/altered SF-36 } \\
\text { Energy/fatigue } \\
\text { Pain } \\
\text { Social function }\end{array}$ & $\begin{array}{l}\text { Disease-specific measures } \\
\text { Blader Control Scale } \\
\text { Bowel Control Scale } \\
\text { Impact of Visual } \\
\text { Functioning Scale } \\
\text { Mental Health Inventory } \\
\text { Modified Fatige Impact } \\
\text { Scale } \\
\text { MOS Modified Social } \\
\text { Support Scale } \\
\text { MOS Pain Effects Scale } \\
\text { Perceived Deficits } \\
\text { Questionnaire } \\
\text { Sexual Satisfaction Scale } \\
\end{array}$ & $\begin{array}{l}\text { Disease - specific } \\
\text { measures } \\
\text { Activity of daily living } \\
\text { Copins } \\
\text { Psychological well - being } \\
\text { Relationship, health- care } \\
\text { system } \\
\text { Relationship, family } \\
\text { Relationship, friends } \\
\text { Rejection } \\
\text { Sentimental and sexual life } \\
\text { Symptoms }\end{array}$ \\
\hline & New & & \\
\hline & Cognitive function & & \\
\hline & Health distress & & \\
\hline & Overall quality of life & & \\
\hline & Sexual function & & \\
\hline
\end{tabular}

Abbreviations: MOS - Medical Outcomes Study; SF-36 - Medical Outcomes Study 36-item Short Form Health Status Survey 
Comparing several selected studies evaluating the quality of life in patients with MS (MSQOL); the differences in overall quality of life were found to be minimal. The overall quality of life in patients was evaluated as 50.50 (5), 59.39 (8), 58.20 (13) (Table 3).

\section{Conclusion}

In this article we have compared and analyzed several measuring tools evaluating the quality of life in patients with MS. Two principal and one complex measuring tools within a multi-dimensional construct evaluating the quality of life are: the
MSQOL, the HRQOL and the MUSIQOL respectively. The MSQOL is a multi-dimensional health-related quality of life measure that combines both generic and MS-specific items into a single instrument. The HRQOL is a multi-dimensional construct that includes aspects of life quality or function affected by health status such as physical health and symptoms; psychosocial factors; psychiatric conditions. The MUSIQOL evaluates the quality of life in 9 dimensions (subscales): activities of daily living; psychological well-being; symptoms; relationships with friends; relationships with

Table 3. Comparing several selected studies, evaluating the quality of life in patients with MS

\begin{tabular}{|c|c|c|c|c|c|c|}
\hline Indicator & \begin{tabular}{|c|} 
Tripoliti et \\
al. $2007(25)$
\end{tabular} & $\begin{array}{c}\text { Casetta et al. } \\
2009(5)\end{array}$ & $\begin{array}{c}\text { Forbes et al. } \\
2006(7)\end{array}$ & $\begin{array}{l}\text { Patti et al. } \\
2007 \text { (17) }\end{array}$ & $\begin{array}{c}\text { Füvesi et al. } \\
2008(8)\end{array}$ & $\begin{array}{l}\text { Miller et al. } \\
2005 \text { (13) }\end{array}$ \\
\hline \multicolumn{7}{|c|}{ 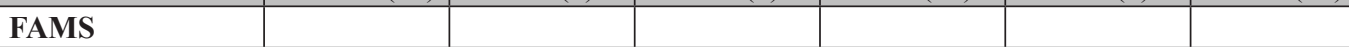 } \\
\hline Mobility & 26.16 & & & & & \\
\hline Symptoms & 71.07 & & & & & \\
\hline $\begin{array}{l}\text { Emotional well } \\
\text { being }\end{array}$ & 61.86 & & & & & \\
\hline Contentment & 51.52 & & & & & \\
\hline $\begin{array}{l}\text { Thinking and } \\
\text { fatigue }\end{array}$ & 49.51 & & & & & \\
\hline Family well being & 73.57 & & & & & \\
\hline Total & 55.61 & & & & & \\
\hline \multicolumn{7}{|l|}{ MSQOL } \\
\hline Overall Quality & & 50.50 & & & 59.39 & 58.20 \\
\hline Cognitive Function & & 78.75 & & & 75.88 & 73.30 \\
\hline Health Distress & & 65.00 & & & 52.94 & 58.50 \\
\hline Sexual Function & & 89.25 & & & 73.36 & 72.90 \\
\hline Sexual Function & & 75.00 & & & 59.16 & 62.20 \\
\hline \multicolumn{7}{|l|}{ MSIS } \\
\hline Physical impact & & & 57.20 & & & \\
\hline $\begin{array}{l}\text { Psychological } \\
\text { impact }\end{array}$ & & & 46.20 & & & \\
\hline \multicolumn{7}{|l|}{ QoL SF-36 } \\
\hline $\begin{array}{l}\text { Physical } \\
\text { functioning }\end{array}$ & & & & 49.00 & & \\
\hline Role physical & & & & 46.00 & & \\
\hline Role emotional & & & & 58.00 & & \\
\hline Social functioning & & & & 67.00 & & \\
\hline Bodily pain & & & & 69.00 & & \\
\hline Mental health & & & & 60.00 & & \\
\hline Vitality & & & & 48.00 & & \\
\hline General health & & & & 46.00 & & \\
\hline
\end{tabular}


family; sentimental and sexual life; coping; rejection; relationships with a healthcare system.

\section{References}

1. BANDARI, DS, VOLLMER, T., KHATRI, BO et al. (2010) Assessing Quality of Life in Patients with Multiple Sclerosis. Int J MS Care, no. 12 p 34-41.

2. BAUMSTRACK, K, BUTZKUEVEN, H, FERNANDEZ, O et al. (2013) Responsiveness of the Multiple Sclerosis International Quality of Life Questionnaire to disability change: a longitudinal study. Health Qual Life Outcomes, no. 11 p 1-9.

3. BUCHANAN, RJ, HUANG, C, KAUFMAN, M (2010) Health-Related Quality of Life Among Young Adults with Multiple Sclerosis. Int J MS Care, no. 12 p 190-199.

4. CARNICKA, Z, KLOBUCNIKOVA, K, SIRIAK, P et al. (2013) Epilepsy in patients with multiple sclerosis (in Czech). Neurol prax, 14 no. 2 p 86-89.

5. CASETTA, I, RIISE, T, NORTVEDT, WM et al. (2009) Gender differences in health-related quality of life in multiple sclerosis. Mult Scler, 15 no. 11 p 1339-1346.

6. FISCHER, JS, LAROCCA, NG, MILLER, $\mathrm{DM}$ et al. (1999) Recent developments in the assessment of quality of life in multiple sclerosis (MS). Mult Scler, 5 no. 4 p 251259.

7. FORBES, A, WHILE, A, MATHES, L et al. (2006) Health problems and health related quality of life in people with multiple sclerosis. Clin Rehabil, 20 no. 1 p 67-78.

8. FÜVESI, J, BENCSIK, K, BENEDEK, K et al. (2008) Cross-cultural adaptation and validation of the 'Multiple Sclerosis Quality of Life Instrument' in Hungarian. Mult Scler, 14 no. 3 p 391-398.

9. HORAKOVA, D, KALINCIK, T, DUSANKOVA, JB et al. (2012) Clinical correlates of grey matter pathology in multiple sclerosis. BMC Neurol no. 12 p 1-10.
10. ISAKSSON, AK, AHLSTROM, G, GUNNARSSON, LG (2005) Quality of life and impairment in patients with multiple sclerosis. J Neurol Neurosurg Psychiatry no.76 no. 1 p 64-69.

11. KLIMOVA, E, CVENGRosovA, A, DANOVA, $M$ et al. (2015) Medical management of patient with highly active relapsing/remitting multiple sclerosis (RRMS) and pregnancy. Case report and discussion (in Slovak). Neurologia, 10 no. 2 (Suppl) p 5-9.

12. KLIMOVA, E (2008) Clinicaly isolated syndrome and sclerosis multiplex (in Slovak). Ambulantná terapia, 6 no.1 p 28-32.

13. MILLER, A, DISHON, S (2005) Health-related quality of life in multiple sclerosis: psychometric analysis of inventories. Multiple Sclerosis, 11 no. 4 p 450-458.

14. MULTIPLE SCLEROSIS INTERNATIONAL FEDERATION (2013) Atlas of MS 2013. Mapping multiple sclerosis around the world. London: MSIF p 1-28.

15. NICHOLL, CR, LINCOLN, NB, FRANCIS, VM et al. (2001) Assessing quality of life in people with multiple sclerosis. Disabil Rehabil, 23 no. 4 p. 597-603.

16. NATIONAL MULTIPLE SCLEROSIS SOCIETY (2015) Multiple Sclerosis Quality of Life Inventory (MSQLI). Atlanta: NMSS.

17. PATTI, F, AMATO, MP, BATTAGLIA, MA et al. (2007) Caregiver quality of life in multiple sclerosis: a multicentre Italian study. Mult Scler, 13 no. 3 p 412-419.

18. RIAZI, A, HOBART, JC, LAMPING, DL et al. (2002) Multiple Sclerosis Impact Scale (MSIS-29): reliability and validity in hospital based samples. J Neurol Neurosurg Psychiatry, 73 no. 6 p 701-704.

19. ROSATI, G (2001) The prevalence of multiple sclerosis in the world: an update. Neurol Sci, 22 no. 2 p 117-139.

20. SAMOHYL, M, LISY, L, JURKOVICOVA, J ( 2014) The impact on nutrition in treatment of multiple sclerosis (in Slovak). Neurologia, 9 no. 1 p 46-49. 
21. SAMOHYL, M, LISY, L., RAMS, R et al (2015) Active ingredient of marijuana has no effect on the multiple sclerosis progression (in Slovak). Neurologia, 10 no. 1 p 7-9.

22. SAMOHYL, M, LISY, L, RAMS, R et al. (2015) The nutritional factors affecting epigenetic regulation in the multiple sclerosis pathogenesis (in Slovak). Neurologia, 10 no. 2 p 69-73.

23. SAMOHYL, M (2014) Quality of health care (in Slovak) Postgradualni med, 16 no. 8 p 887-892.

24. SØRENSEN, J., BAY, J, DAMSGAARD, T et al. (2011) Validation of the Danish Version of unctional Assessment of Multiple
Sclerosis: A Quality of Life Instrument p. 1-8.

25. TRIPOLITI, E, CAMPBELL, C, PRING, T et al (2007) Quality of life in multiple sclerosis: Should Glinicians trust proxy ratings? Multiple Sclerosis 13 no. 9 p 1190-1194.

\section{Corresponding author}

MUDr. Ladislav Simor

Dept. of Revision Medicine and Dentistry

Slovak Medical University

Limbova 12

83303 Bratislava

Slovak Republic

e-mail: ladislav.simor@gmail.com 